\title{
Observation of internal structures of snow covers with a ground-penetrating radar
}

\author{
TAtsuya YAMAMOTO, ${ }^{1,2}$ Keniahi MATSUOKA, ${ }^{1,2^{*}}$ Renji NARUSE ${ }^{2}$ \\ ${ }^{1}$ Graduate School of Environmental Earth Science, Hokkaido University, Sapporo 060-0810, Japan \\ E-mail:tatuya@pop.lowtem.hokudai.ac.jp \\ ${ }^{2}$ Institute of Low Temperature Science, Hokkaido University, Sapporo 060-0819, Japan
}

\begin{abstract}
To complement a technique to detect internal structures of seasonal snow covers and glacier firn with ground-penetrating radar (GPR), we carried out calibration experiments and an observation of winter snow cover $(5.7 \mathrm{~m}$ thick dry snow with numerous ice layers) with an $800 \mathrm{MHz}$ GPR. In particular, we aimed to discriminate periodic noise, which is inherent in GPR, from radar echoes and to obtain a relationship between the observed reflection strength and the magnitude of density contrasts. Experiments were done in air to evaluate noise levels and receiver characteristics of this system. Based on these, we removed noise from radar echoes in the snow-cover observation. We recognized numerous marked echoes in a noise-free radargram. The depths of these echoes coincided roughly with those of large density contrasts observed in the snow pit. Thus, we argue that the echoes correspond to thin ice layers. Furthermore, the minimum density contrasts detected by this GPR are found to vary from about 100 to $250 \mathrm{~kg} \mathrm{~m}^{-3}$ at $1-6 \mathrm{~m}$ depth in the seasonal snow cover.
\end{abstract}

\section{INTRODUCTION}

Snow depositional patterns in mountain regions are irregular and complicated due to wind directions in storms, topography and vegetation. It is essential to know the spatial distribution of snow deposition for the study of glacier mass balances and for the estimation of water resources from seasonal snow. However, conventional surveys with snow coring or snow pits are not suitable for investigations over wide areas. Thus, the development of remote-sensing techniques for snow covers has been much demanded.

Ground-penetrating radar (GPR) is one of the most effective methods for studying spatial variations of snow, because portable GPRs enable us to carry out quick surveys for long distances without disturbing snow covers. Kohler and others (1997) made a GPR survey in the accumulation area of Handangerjøkullen, Norway, and showed that depths of radar reflections coincided well with the depths of permittivity contrasts due to density variation in the upper $10 \mathrm{~m}$ snow layer. Pinglot and others (2001) detected snow and ice interfaces with GPR over a vast area in Austfonna, Svalbard, and estimated the distribution of mass balance. In addition, GPRs have been widely used for structural and hydrological studies of glaciers: namely entrained subglacial sediments at Bakaninbreen, Svalbard (Murray and others, 1997), buried crevasses in ice streams in West Antarctica (Retzlaff and Bentley, 1993; Clarke and Bentley, 1994), the hydrothermal structure of a polythermal glacier in Svalbard (Moore and others, 1999), and water content within Falljökull, Iceland (Murray and others, 2000). How-

\footnotetext{
* Present address: Department of Earth and Space Sciences, Box 351310, University of Washington, Seattle, WA 981951310, U.S.A.
}

ever, these studies were mainly based on travel time, i.e. spatial variation of depths of reflectors. A quantitative method to interpret radar-echo intensity is not yet well established. Moreover, because GPR data contain periodic noise, which is inherent in the nature of GPR, it is important to remove the noise for quantitative radar-echo analyses.

The present paper aims at evaluating and improving the technique and method of investigating internal structures of snow covers using GPR. First, we carried out calibration experiments with the GPR in an open space to determine a noise level and calibrate the receiver. Second, we made a radar survey of winter snow cover in a mountain region, and interpreted radar echoes based on the calibration experiments. Finally, we compared the reflection strength with snow-pit data to discuss minimum detectable density contrasts in snow.

\section{METHODS}

The GPR used for this study is an $800 \mathrm{MHz}$ Ramac GPR system manufactured by Måla GeoScience, Sweden. This frequency corresponds to a wavelength of $0.32 \mathrm{~m}$ in snow of density $200 \mathrm{~kg} \mathrm{~m}^{-3}$, and $0.26 \mathrm{~m}$ in $500 \mathrm{~kg} \mathrm{~m}^{-3}$. A performance test of this GPR at Athabasca Glacier, Canada, is briefly described by Matsuoka and others (2003).

\subsection{Experiments for radar calibration}

Two kinds of calibrating experiments were conducted in the open space of the experimental farm of Hokkaido University, Sapporo, Japan. First, the GPR transmitter was placed upside down on the ground. Thus, most of the transmitted wave was radiated toward the sky. Received signals in this experiment were regarded as the noise level of the instrument. 


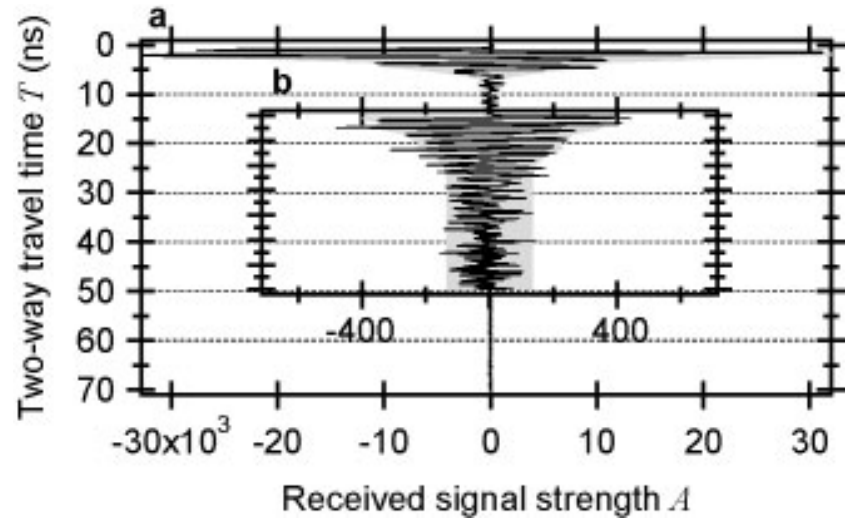

Fig. 1. Time series of received signals for the GPR projected upward in the open space. Signal level for $15<T<50$ ns is enlarged in panel $b . T=70$ ns corresponds to the distance of $10.5 \mathrm{~m}$ in air. Estimated noise level is illustrated by a gray zone.

Secondly, in order to calibrate the receiver, we put a metal board ( $2 \mathrm{~m}$ by $1 \mathrm{~m}$ ) in the air, and radio waves were transmitted toward the board which was placed successively at 16 points of distances $0.8-5 \mathrm{~m}$ from the transmitter. The received power $P_{\mathrm{r}}$ is affected by dielectric properties of the medium and system parameters. The fundamental relation among them is described by the radar equation as

$$
P_{\mathrm{r}}=\frac{P_{\mathrm{t}} G^{2} \lambda^{2} \sigma^{2}}{(4 \pi)^{2}(2 d)^{2}} \exp (-2 \alpha d),
$$

where $P_{\mathrm{t}}$ is the transmitting power, $G$ is the antenna gain, $\lambda$ is the wavelength in a vacuum, $\sigma$ is the scattering cross-section of the target, $\alpha$ is the attenuation coefficient and $d$ is the distance (depth) of the target (e.g. Bogorodsky and others, 1985). The Ramac GPR (like most other GPRs) does not detect signals: the received signal is a time series of the received voltage $V_{\mathrm{r}}\left(=\sqrt{P_{\mathrm{r}} Z} ; Z\right.$ : antenna impedance). Then we obtain a radar equation for GPR data analysis as

$$
V_{\mathrm{r}}=\sigma S \frac{\exp (-\alpha d)}{d} \text {. }
$$

Here, $S$ is composed of system parameters $\left(S^{2}=P_{\mathrm{t}} G^{2} Z \lambda^{2} /\right.$ $\left.(8 \pi)^{2}\right)$. In the case of open space, $\alpha=0$ and $V_{\mathrm{r}}$ is inversely proportional to $d$. To examine characteristics of the receiver, we measured the GPR signal strength $A$ (16-bit digital values of system output) for various distances $d$. From this experiment, a relation between $A$ and $V_{\mathrm{r}}$, and the numerical value of $S$ were obtained.

\subsection{Observation of seasonal snow}

We conducted a field observation of seasonal snow cover at Murodou-daira $\left(36^{\circ} 34^{\prime} \mathrm{N}, 137^{\circ} 36^{\prime} \mathrm{E}\right.$; $2450 \mathrm{~m}$ a.s.l.), Tateyama, Japan, in April 2001. The snow-cover thickness was $5.7 \mathrm{~m}$, and the snow was dry except for the surface $15 \mathrm{~cm}$ layer. On a wide, flat area, we carried out a continuous GPR measurement along a survey line of about $10 \mathrm{~m}$. The antenna unit was towed on the snow surface; this disturbed snow within the top $10 \mathrm{~cm}$. Near the survey line, we made a $5.7 \mathrm{~m}$ deep snow pit to measure the stratigraphy, density, grain-size and temperature in the snow cover.

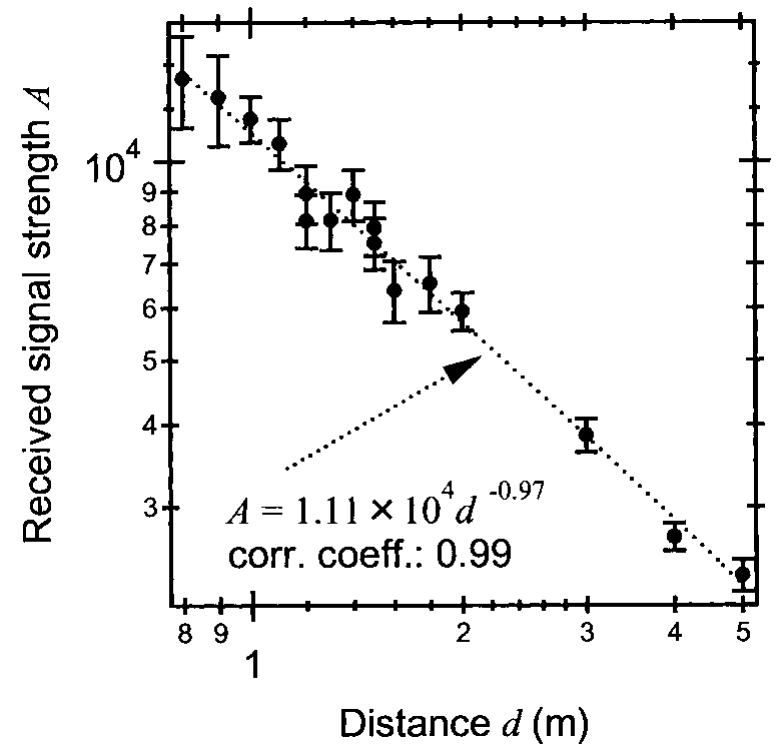

Fig. 2. Log-log plot of the distance dependency of GPR signal strength. Error bars indicate the noise level at each depth.

\section{RESULTS}

\subsection{Calibrating experiments}

\subsubsection{Noise level of GPR}

Figure 1 shows received signal strength $A$ of the GPR against the two-way travel time $T$ obtained by the first experiment. After the direct wave from the transmitting antenna to the receiver in $T<5 \mathrm{~ns}$, two distinct zones are specified: one is a zone of decreasing $A$ with $T$ (about 5 $<T<30 \mathrm{~ns}$ ), and the other is a zone of almost stable $A$ $(30 \mathrm{~ns}<T)$. When the stacking number increases, $A$ becomes a single wave form in the former region, whereas in the latter $A$ decreases with the stacking number. Therefore, we regard the former as periodic noise following the direct wave, and the latter as white noise. We assume the noise level as shown by the gray zone in Figure 1, namely the maximum periodic noise in $T<30 \mathrm{~ns}$ and three times the standard deviation of $A$ in $T>30$ ns. We carried out five sets of this experiment on different days, and confirmed the stability of the instrument.

If the stacking number increases, the effect of white noise decreases. However, this requires a longer measurement time and reduces mobility in the field. Thus, we set the stacking number at 8 . It took about $0.08 \mathrm{~s}$ to obtain one dataset for the typical case (sampling interval of $0.1 \mathrm{~ns}$ within the time window of $100 \mathrm{~ns}$ ).

\subsubsection{Distance dependence of GPR signal strength}

In Figure 2, the distance dependence of GPR signal strength $A$ is shown, as obtained from the experiment with the reflection plate. The relation was fitted with a power function of distance: $A=1.11 \times 10^{4} d^{0.97}$ (correlation coefficient: 0.99 ). This means that $A$ is linearly proportional to $V_{\mathrm{r}}$, because $V_{\mathrm{r}}$ is inversely proportional to $d$ in the air $(\alpha=0$; Equation (2)). Furthermore, since the Fresnel reflectivity $R$ is equal to 1 in this case (metal reflector), $S$ is obtained as $1.11 \times 10^{4}$.

\subsection{GPR signals from within seasonal snow}

Figure 3 a displays a raw radargram along the $10 \mathrm{~m}$ survey line. We clearly observed the snow/soil interface at $5.7 \mathrm{~m}$ 


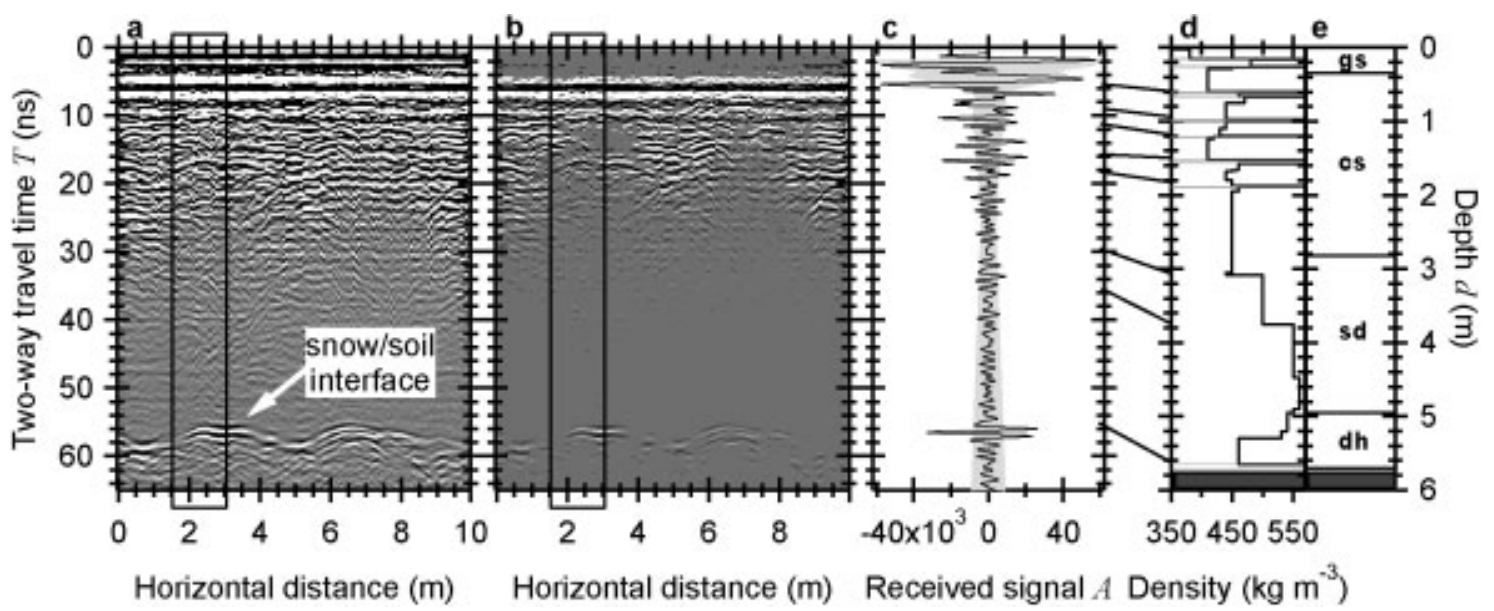

Fig. 3. Results of seasonal snow survey. (a) Radargram along the $10 \mathrm{~m}$ survey line to show raw A data. ( $b$ ) Noise-free radargram. Squares in ( a) and (b) indicate the location of the snow pit. (c) Radar echoes at the snow-pit site (solid line) and noise level (gray zone). Strengths of received signals and noise levels are modified by multiplying the depth to compensate for geographical spreading of radio waves. (d) Distributions of snow density and ice layers (horizontal gray lines). Density is obtained for each sub-layer with uniform snow type and grain-size. Straight lines between $(c)$ and $(d)$ show the equivalence of two-way travel time and depth of major ice layers and density contrasts. (e) Stratigraphy of the snow cover. Snow types are, from the surface to the bottom, granular snow (marked by gs), compacted snow (cs), solid-type depth hoar (sd) and depth hoar (dh).

depth, which was confirmed by a pit study. However, this radargram includes not only radar echoes but also noise. Removing the periodic and white noise, namely setting $A$ smaller than the experimental noise level to zero (Fig. 1), a noise-free radargram is shown in Figure 3b. Figure 3c indicates radar echoes at the center of the $1.5 \mathrm{~m}$ wide snow pit. Horizontal band structures in $T<7$ ns are mostly caused by the direct wave and the periodic noise. Following this, $A$ exceeds the noise level and varies horizontally and vertically (10 ns $<T<24 \mathrm{~ns}$ ), which suggests that the GPR detects the internal structure of snow covers. On the other hand, in the layers of $24<T<55 \mathrm{~ns}$, no significant fluctuations in $A$ were recognized.

Snow-pit data are shown in Figure $3 d$ and e. Snow density changes from $350 \mathrm{~kg} \mathrm{~m}^{-3}$ in the upper layer to about $550 \mathrm{~kg} \mathrm{~m}^{-3}$ at $4-5 \mathrm{~m}$ depth. There are a number of ice layers, mostly thinner than $2 \mathrm{~cm}$ but about $5 \mathrm{~cm}$ thick near the bottom. The largest density contrast between snow layers is measured as $70 \mathrm{~kg} \mathrm{~m}^{-3}$ at $5.3 \mathrm{~m}$ depth. We used this density profile to convert $T$ into $d$, as shown with straight lines between Figure 3c and d. The snow type was mostly compacted snow in the shallow layer and solid-type depth hoar in the deeper layer.

\section{DISCUSSION}

Based on calibration experiments and snow observations, we discuss a relationship between the density contrasts within snow and GPR signal strength. Among the system parameters, impedance $Z$ depends on the snow surface condition. However, since the study line is short $(10 \mathrm{~m})$, we assume $Z$ to be constant for all measurements. Also, we apply the noise level, the linearity of $A$ with $V_{\mathrm{r}}$, and $S$ obtained by radar calibration in air to snow measurements; although it is not clear whether these assumptions are reasonable, our result seems to justify them (see below). Radiowave absorption rate within snow $(\alpha)$ is another unknown parameter. Dielectric measurements of ice at temperatures $<-10^{\circ} \mathrm{C}$ (Fujita and others, 2000) and Arrhenius dependence of conductivity suggest that absorption of radio waves within ice at $-5^{\circ} \mathrm{C}$ is only $4 \%$ when the ice depth is $5 \mathrm{~m}$. Therefore, we neglect the absorption within snow. Under these assumptions, we obtain $\sigma$ from A $\left(\sigma=A d /\left(1.11 \times 10^{4}\right)\right.$ derived from Equation (2)), which is shown in Figure 4. The solid line in the figure indicates a detection limit, which is equivalent to $\sigma$ when we put the noise level into $A$.

Figure 4 also shows the Fresnel reflectivity $R$ derived from the density profile using an experimental relation between density and permittivity (Tiuri and others, 1984) and a simple theoretical relation between $R$ and permittivity changes (Paren, 1981). We calculated $R$ for all density contrasts. If the reflection surface (i.e. density contrast horizon) is flat, $\sigma$ equals $R$, and if the surface undulates $\sigma$ is proportional to $R$ (Ulaby and others, 1981).

We observed significantly large values of $\sigma$ at depths of $1-2 \mathrm{~m}$ and around $5.7 \mathrm{~m}$. Values of $R$ are also relatively large at these depths. However, the depth of $\sigma$ does not exactly coincide with that of $R$. This is probably because of interference among reflected waves from many ice layers; spacing of ice layers varies from 1 to $34 \mathrm{~cm}$, most of which are much smaller than one wavelength. Numerous $R$ values smaller than 0.03 were found at depths of $3-5.5 \mathrm{~m}$, where we did not obtain significant $\sigma$ values. Near the bottom (around $5.7 \mathrm{~m}), \sigma$ is about two or three times $R$. Reflections off the deep ice layers may interfere with reflections off the soil/ snow interface. Except for this large depth, $\sigma$ and $R$ show similar magnitudes at depths of $1-2 \mathrm{~m}$. These imply that experimental assumptions based on radar calibrations in the air (e.g. noise level and $S$ ) are reasonable. For simplicity, we assume $\sigma=R$ for the further discussion.

The detection limit in Figure 4 indicates how small the smallest density contrasts that can be detected with the GPR are. First, we consider density contrasts within snow. The profile of the detection limit shows that the GPR detects smaller $\sigma$ in $20<T<39 \mathrm{~ns}$ (equivalent to $2-4 \mathrm{~m}$ depth in this study). The minimum $\sigma(=0.032)$ corresponds to density contrasts of $300-400 \mathrm{~kg} \mathrm{~m}^{-3}$, and $400-510 \mathrm{~kg} \mathrm{~m}^{-3}$. Although this estimate is very approximate, we suggest that the minimum detectable density contrast with this GPR is $>100 \mathrm{~kg} \mathrm{~m}^{-3}$. It varies from about 100 to $250 \mathrm{~kg} \mathrm{~m}^{-3}$ at $1-$ $6 \mathrm{~m}$ depth in the studied seasonal snow cover. 


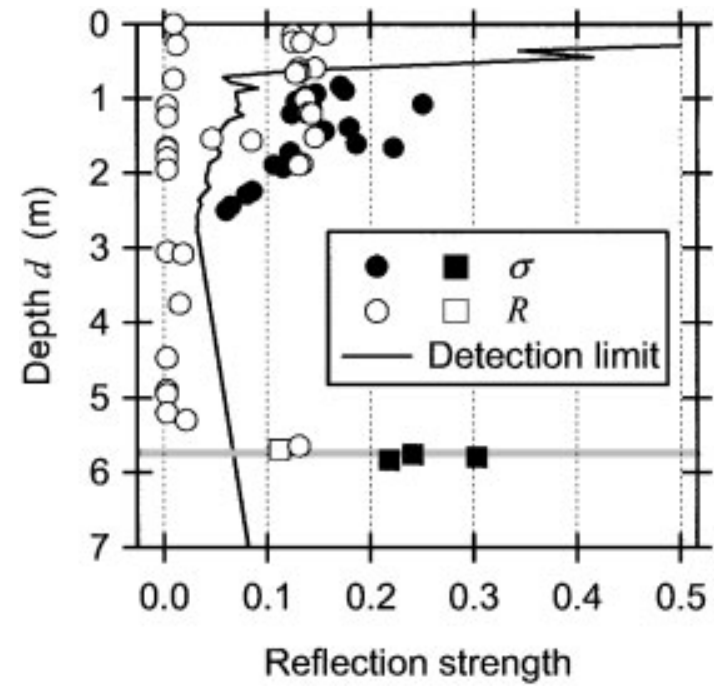

Fig. 4. Depth variations in observed reflection strength $\sigma$ (solid circles) derived from measured A with some assumptions ( see text), and theoretical reflection strength, namely the Fresnel reflectivity $R$ (open circles), calculated at all possible reflection interfaces such as density changes and ice layers. $\sigma$ and $R$ for the snow and soil interface (horizontal gray line) are shown with solid and open squares, assuming the permittivity of soil to be 5 . The solid line indicates the minimum detection limit of the instrument obtained from the open-space experiment (Fig. 1). Two-way travel time was converted to depth with the density profile ( Fig. 3c).

Second, we consider the snow/ice interface. An interface between ice $\left(917 \mathrm{~kg} \mathrm{~m}^{-3}\right)$ and snow $\left(400 \mathrm{~kg} \mathrm{~m}^{-3}\right)$ gives $R=$ 0.14 . The GPR can detect this only if the interface exists at $T>7 \mathrm{~ns}(d>0.7 \mathrm{~m}$ in this study). If the snow density is smaller than that, ice layers can be detected over a larger depth range. This indicates that the GPR detects ice layers within typical dry seasonal snow covers with densities $<400 \mathrm{~kg} \mathrm{~m}^{-3}$ except for the top several tens of centimeters. Though radio-wave scattering within real snow is much more complex than we assumed here $(\sigma=R), \sigma$ and $R$ are seen to be of almost the same magnitude in layers $1-2 \mathrm{~m}$ deep (Fig. 4).

\section{GONGLUSIONS}

A combination of calibration experiments with winter snow observations provides basic knowledge on the GPR method for investigating internal structures of seasonal snow and glacier firn. Calibration experiments give a reference to distinguish real radar echoes from GPR signals which contain periodic noise and white noise. The noise level changes with two-way travel time, and it shows a minimum for $2-4 \mathrm{~m}$ depth in normal snow covers. Moreover, GPR signal strengths matched the expected magnitudes from the radar equation: they are inversely proportional to distance. This suggests that, in addition to two-way travel time, signal strength can provide useful glaciological information. Rough agreements between GPR-derived and density-derived reflectivities support this idea. Under optimum conditions, the GPR is capable of detecting density contrasts $>100 \mathrm{~kg} \mathrm{~m}^{-3}$. Although interference between radio waves reflected from numerous ice layers prevents the exact determination of ice-layer depths, we expect that the GPR detects ice layers in seasonal snow covers.

Commercial GPRs are available at various frequencies between tens of $\mathrm{MHz}$ and several GHz. The Ramac GPR, for example, has five frequency units $(100,250,500,800$ and $1000 \mathrm{MHz}$ ). We did not investigate which frequency is best for seasonal snow and glacier firn surveys in this study. In general, however, a radar lower frequency has lower resolution. If one uses a higher frequency, radar echoes may be too complex to interpret due to scattering within heterogeneous snow, and penetration depth will be much smaller in wet snow. Thus, we argue that a frequency around 500$800 \mathrm{MHz}$ is most useful for investigating seasonal snow and glacier firn with thickness smaller than about $10 \mathrm{~m}$.

\section{ACKNOWLEDGEMENTS}

We express our sincere thanks to K. Kawada and the students of Toyama University for cooperative field measurements at Murodou-daira and for providing us with the snow-pit data. We are also grateful to K. Yokoyama of the National Agricultural Research Center, K. Konya, E. Issenko and N. Sato of Hokkaido University, and T. Aoki of Kanazawa University for assistance in experiments. We also thank members of the Glacier and Ice Sheet Research Group, Institute of Low Temperature Science (ILTS), for helpful discussion, and an anonymous reviewer for comments. This study is supported by a grant from the Ministry of Education, Science, Sports and Culture of Japan (No. 12554015) and a fund of Leadership of the ILTS.

\section{REFERENGES}

Bogorodsky, V.V., C. R. Bentley and P. E. Gudmandsen. 1985. Radioglaciology. Dordrecht, etc., D. Reidel Publishing Co.

Clarke, T. S. and C. R. Bentley. 1994. High-resolution radar on Ice Stream B2, Antarctica: measurements of electromagnetic wave speed in firn and strain history from buried crevasses. Ann. Glaciol., 20, 153-159.

Fujita, S., T. Matsuoka, T. Ishida, K. Matsuoka and S. Mae. 2000. A summary of the complex dielectric permittivity of ice in the megahertz range and its applications for radar sounding of polar ice sheets. In Hondoh, T., ed. Physics of ice core records. Sapporo, Hokkaido University Press, 185-212.

Kohler, J., J. Moore, M. Kennett, R. Engeset and H. Elvehøy. 1997. Using ground-penetrating radar to image previous years' summer surfaces for mass-balance measurements. Ann. Glaciol., 24, 355-360.

Matsuoka, K., T. Aoki, T. Yamamoto and R. Naruse. 2003. Field-performance tests of a portable low-frequency ice-penetrating radar and a ground-penetrating radar at Athabasca Glacier, Canadian Rockies. Bull. Glaciol. Res. 20, 49-55.

Moore, J.C. and 8 others. 1999. High-resolution hydrothermal structure of Hansbreen, Spitsbergen, mapped by ground-penetrating radar. $\mathcal{f}$. Glaciol., 45(151), 524-532.

Murray, T., D. L. Gooch and G.W. Stuart. 1997. Structures within the surge front at Bakaninbreen, Svalbard, using ground-penetrating radar. Ann. Glaciol., 24, 122-129.

Murray, T., G.W. Stuart, M. Fry, N. H. Gamble and M. D. Crabtree. 2000. Englacial water distribution in a temperate glacier from surface and borehole radar velocity analysis. F. Glaciol., 46(154), 389-398.

Paren, J. G. 1981. Correspondence. Reflection coefficient at a dielectric interface. F. Glaciol., 27(95), 203-204.

Pinglot, J. F., J. O. Hagen, K. Melvold, T. Eiken and C. Vincent. 2001. A mean net accumulation pattern derived from radioactive layers and radar soundings on Austfonna, Nordaustlandet, Svalbard. 7. Glaciol., $47(159), 555-566$.

Retzlaff, R. and C. R. Bentley. 1993. Timing of stagnation of Ice Stream C, West Antarctica, from short-pulse radar studies of buried surface crevasses. f. Glaciol., 39(133), 553-561.

Tiuri, M. T., A. H. Sihvola, E. G. Nyfors and M. T. Hallikainen. 1984. The complex dielectric constant of snow at microwave frequencies. IEEE $\mathcal{F}$. Oceanic Eng., OE-9(5), 377-382.

Ulaby, F. T., R. K. Moore and A. K. Fung. 1981. Microwave remote sensing, active and passive. Vol. 1. Fundamentals and radiometry. Reading, MA, AddisonWesley Publishing Co. 